\title{
Environment-assisted Cracking Behavior of Friction Stir Welded AA 2195
}

\author{
Lu Gan and Efstathios I. Meletis \\ Materials Science and Engineering Program, Mechanical Engineering Department \\ Louisiana State University, Baton Rouge, LA 70803, USA
}

\begin{abstract}
Friction stir welding (FSW) was utilized to join AA 2195. The microstructures of the various FSW zones were characterized by transmission electron microscopy. The environment-assisted cracking (EAC) behavior of the welded alloy was studied by conducting slow extension rate experiments (SERT) under different environmental conditions. The results of constant immersion and dynamic charging experiments in $\mathrm{NaCl}$ solution showed no ductility reductions for the FSW Al 2195 alloy. Pre-exposure in $\mathrm{NaCl}$ solution under alternate immersion followed by SERT revealed a certain degree of environmental susceptibility that increased with increasing pre-exposure time. EAC was associated with the heat-affected zone where coarser $T_{1}$ precipitates were present. The observed behavior was attributed to coarser $T_{1}$ dissolution that can facilitate hydrogen reduction kinetics and ingress in the alloy resulting in susceptibility by a hydrogen embrittlement process.
\end{abstract}

\section{INTRODUCTION}

Friction stir welding (FSW) is an innovative solid-state welding process offering great promise especially in joining Al alloys /1-5/. Previous studies have reported on microstructure and mechanical properties of FSW of conventional aluminum alloys /2, 6-8/ and developments have been recently reviewed by Jata $/ 9 /$. FSW is about to find a number of applications such as on the AA 2195 cryogenic tanks of the Space Transportation System /4/. At present, very little is known about the environment-assisted cracking (EAC) behavior of FSW of AA $2195 / 10,11$. Embrittlement in Al-Li-Cu alloys has been attributed to anodic dissolution $/ 12 /$, hydrogen embrittlement $/ 13 /$ and hydride formation $/ 14 /$. Thus, there is a need at present to develop a better understanding of the EAC behavior of friction stir welded AA2195. Such studies provide also an opportunity to shed more light onto the embrittlement mechanism since new unique microstructures are produced during this joining process. 


\section{EXPERIMENTAL}

Rolled plates ( $5.85 \mathrm{~mm}$ thick) of AA 2195 have been joined along the rolling direction by FSW and were supplied by Lockheed-Martin Space Systems (New Orleans. Louisiana). The nominal composition of the parent alloy was $3.7 \sim 4.3 \% \mathrm{Cu}, 0.8 \sim 1.2 \% \mathrm{Li}, 0.25 \sim 0.6 \% \mathrm{Ag}, 0.25 \sim 0.8 \% \mathrm{Mg} .0 .08 \sim 0.16 \% \mathrm{Zr}$ and balance Al. The parent AA 2195 was in the T8 condition (solution heat treated, water quenched. stretched $-3.5 \%$ and aged for $36 \mathrm{~h}$ at $143^{\circ} \mathrm{C}$ ). The cross sectional macrostructure of FSW AA 2195 is shown in Figure 1. Weldments were characterized using transmission electron microscopy (TEM). Thin foils $(-200 \mu \mathrm{m})$ were prepared by electropolishing in $3: 1$ methanol and nitric acid at about $-30^{\circ} \mathrm{C}$ and an applied voltage of $13 \mathrm{~V}$. Selected area diffraction patterns and centered dark field images were used to characterize the microstructure of the various FSW zones, Fig. I.

EAC susceptibility was studied by conducting tensile slow extension rate testing (SERT) of FSW AA 2195 immersed in $3.5 \% \mathrm{NaCl}$ solution under open-circuit potential (OCP), cathodically charged at $-1500 \mathrm{mV}$ vs. a saturated calomel electrode ( $\mathrm{SCE}$ ), after pre-exposure (PE) under alternate immersion ( $\mathrm{Al}$ ) in $3.5 \%$ $\mathrm{NaCl}$ solution for $\mathrm{I}, 10$ and 30 days, and in air (standard). Tensile specimens were machined in the transverse direction with respect to the weld. The tensile specimens were $15.2 \mathrm{~cm}$ long with a rectangular cross section of $5.85 \mathrm{~mm} \times 10 \mathrm{~mm}$. The initial strain rate during the SERT experiments was $3.3 \times 10^{-5} \mathrm{~s}^{-1}$. During FSW. a $25.4 \mathrm{~mm}$ wide weld zone is produced that is significantly softer than the parent alloy 110,11 . Thus, the weld zone was assumed as the gage length in calculating strain at fracture. Duplicate tests were conducted for all environments.

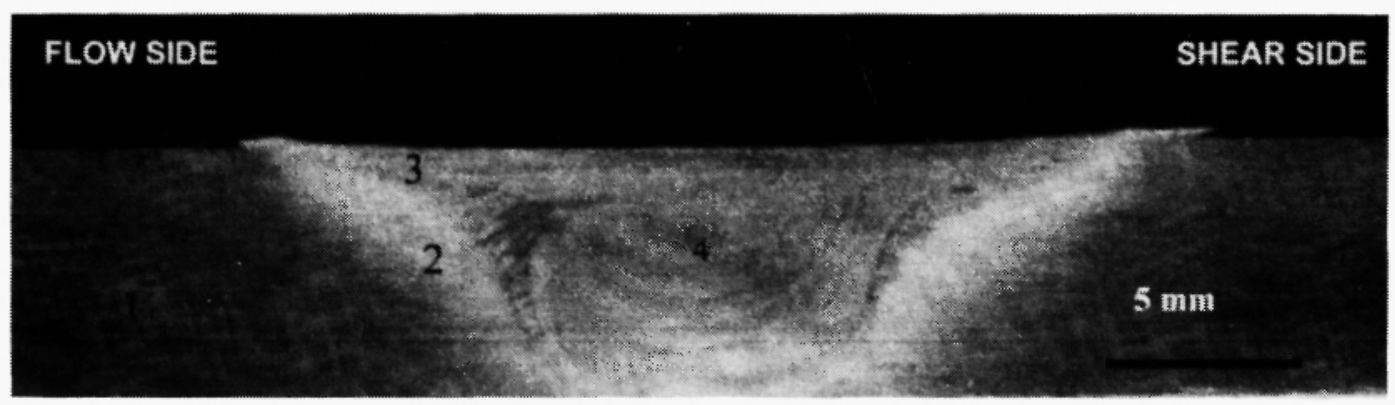

Fig. 1: Cross sectional view indicating typical FSW zones; 1: parent alloy, 2:heat affected zone (HAZ). 3: thermomechanical zone (TMZ), 4: dynamically recrystallized zone (DXZ), 5: re-heated surface zone (SDXZ). 


\section{RESULTS AND DISCUSSION}

\section{Microstructural Characteristics}

The TEM study showed that the parent Al 2195 T8 alloy mainly has an unrecrystallized microstructure due the presence of spherical, coherent $\beta^{\prime}\left(\mathrm{Al}_{3} \mathrm{Zr}\right)$ precipitates. The alloy is primarily strengthened by a fine dispersion of plate shaped $\mathrm{T}_{1}\left(\mathrm{Al}_{2} \mathrm{CuLi}\right)$ precipitates as has been previously reported for similar $\mathrm{Al}-\mathrm{Cu}-\mathrm{Li}$ alloys $/ 13,15,16 \%$. Preferential precipitation of $T_{1}$ at subgrain boundaries was present, a feature that is commonly observed in Al-Cu-Li alloys due to the heterogeneous nucleation of the $\mathrm{T}_{1}$ phase $/ 17 /$. However, the size of $T_{1}$ at subgrain boundaries was significantly smaller than that observed in higher Li content alloys such as $\mathrm{Al} 2090 / 17 /$

TEM examinations carried out in the center. upper section of the FSW processed area showed the presence of an equiaxed recrystallized microstructure with an average grain size of $\sim 3.8 \mu \mathrm{m}$, Figure $2(\mathrm{a})$. $\mathrm{T}_{1}$ precipitates were not present in DXZ. Temperatures during $\mathrm{FSW}$ reach $\sim 480^{\circ} \mathrm{C}\left(900^{\circ} \mathrm{F}\right)$ and according to the Al-Li-Cu equilibrium phase diagram, $T_{1}$ is expected to be resolutionized /18/. Streaking in the $\langle\mid 00\rangle$ direction was evident in the diffraction patterns. Fig. 2(a), suggesting the presence of GP zones resulting from the supersaturated solid solution produced after FSW in this zone. Observations also revealed the presence of $\mathrm{T}_{\mathrm{B}}\left(\mathrm{Al}_{7} \mathrm{C \textrm {C } _ { 4 }} \mathrm{Li}\right)$ and $\beta^{\prime}$ precipitates; however, the population of these phases was much lower than that of $\mathrm{T}_{1}$ in the parent Al 2195 alloy. Furthermore, a high dislocation density was evident in SDXZ implying that permanent deformation may have been introduced by FSW (by the shoulder of the pin tool) after dynamic recrystallization. Finally, a distribution of coarse particles was evident at low magnifications of what appeared to be fragments of intermetallics produced during FSW processing.
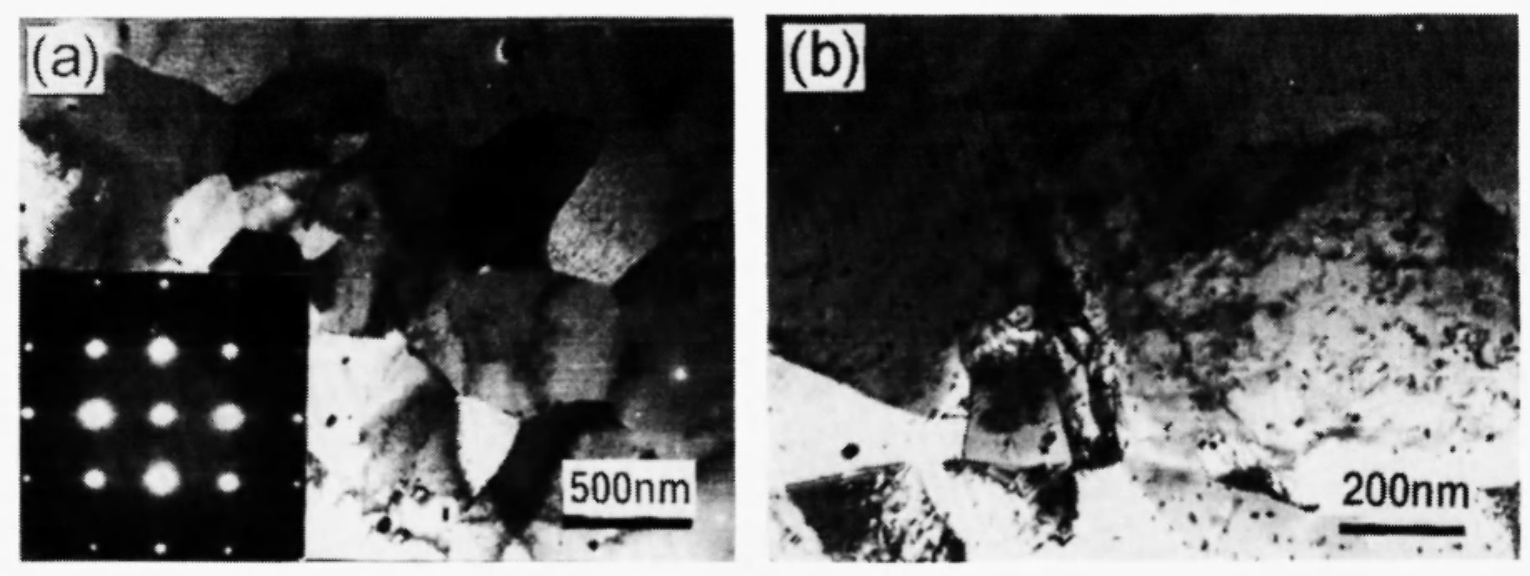

Fig. 2: Bright field image of (a) subgrain structure in DXZ. Inset is the corresponding diffraction pattern (/001/ zone axis) and (b) disperse particles and grain boundary equilibrium phases in TMZ. 
TEM observations in TMZ showed a subgrain size of about 3-3.5 $\mu \mathrm{m}$ and a disperse distribution of large precipitates, Figure 2(b). Strong streaking was also shown along the $\langle 100\rangle$ direction suggesting the growth of GP zones. Examinations showed that besides fragmented intermetallic and $T_{B}$ particles, grain boundary phases were also developed in this zone, Figure 2(b). Finally, TEM observations in the HAZ showed that coarsening of $T_{1}$ precipitates has taken place during FSW processing.

\section{EAC Susceptibility of FSW AA 2195}

The SERT results are shown in Table 1 . The environmental susceptibility was assessed by calculating the degree of embrittlement $\left(D O E=\left[\varepsilon_{a i r}-\varepsilon_{c m}\right] / \varepsilon_{a i r}\right)$. The mechanical properties of friction stir welded Al 2195 were found to be inferior to those of the parent alloy $\left(\sigma_{U 7 s}=83.9 \mathrm{ksi}\right.$ and $\varepsilon_{f}=17.7 \%$ ). Weldable Al alloys typically exhibit a $30 \%$ to $60 \%$ reduction in strength $/ 4 /$. Thus, the losses due to FSW are at the lower end of the range. The reduction in the UTS is due to resolutionization of $T_{1}$ precipitates occurring during FSW processing.

Table 1

SERT results of FSW AA 2195.

\begin{tabular}{|l|c|c|c|}
\hline Environment & $\begin{array}{c}\sigma_{U T S} \\
(\mathrm{ksi})\end{array}$ & $\begin{array}{c}\varepsilon_{f} \\
(\%)\end{array}$ & $\begin{array}{c}\text { DOE } \\
(\%)\end{array}$ \\
\hline Laboratory Air & 61.7 & 9.93 & $\ldots$ \\
\hline $3.5 \% \mathrm{NaCl}, \mathrm{OCP}$ & 61.9 & 10.1 & 0 \\
\hline$-1500 \mathrm{mV}$ (SCE) & 62.2 & 10.1 & 0 \\
\hline PE-Al (1 day) & 61.9 & 9.32 & 6.1 \\
\hline PE-Al (10 days) & 61.4 & 8.59 & 13.5 \\
\hline PE-Al (30 days) & 61.5 & 5.69 & 42.7 \\
\hline
\end{tabular}

$\sigma_{l / 7 s}$ ultimate tensile strength, $\varepsilon_{f}$ : strain-at-fracture

Scanning electron microscopy (SEM) observations showed that fracture for most specimens tends to initiate at the bottom junction line of the weld (joint line of the two panels). It should be noted that during FSW the tip of the pin tool does not completely penetrate the two panels and thus leaves remnants of the original fraying surface and unrecrystallized parent material at the bottom of the weld (4). Fracture typically initiated at the joint line propagated upwards in the shear side following the DXZ/TMZ interface and finally crossed into the DXZ section of the weld. Closer examination showed that the bottom layer exhibited a rather low energy fracture, Figure 3(a). In this bottom layer there is lack of penetration by the tool pin and it is diffusion bonded. The observed relatively flat fracture surfaces are associated with fracture along this 
diffusion-bonded joint. Besides that, the remaining FSW zones in specimens tested in laboratory air showed a ductile fracture mode. The DXZ exhibited ductile fracture with features corresponding to the dimensions of the grain size of this zone, Figure 3(b).
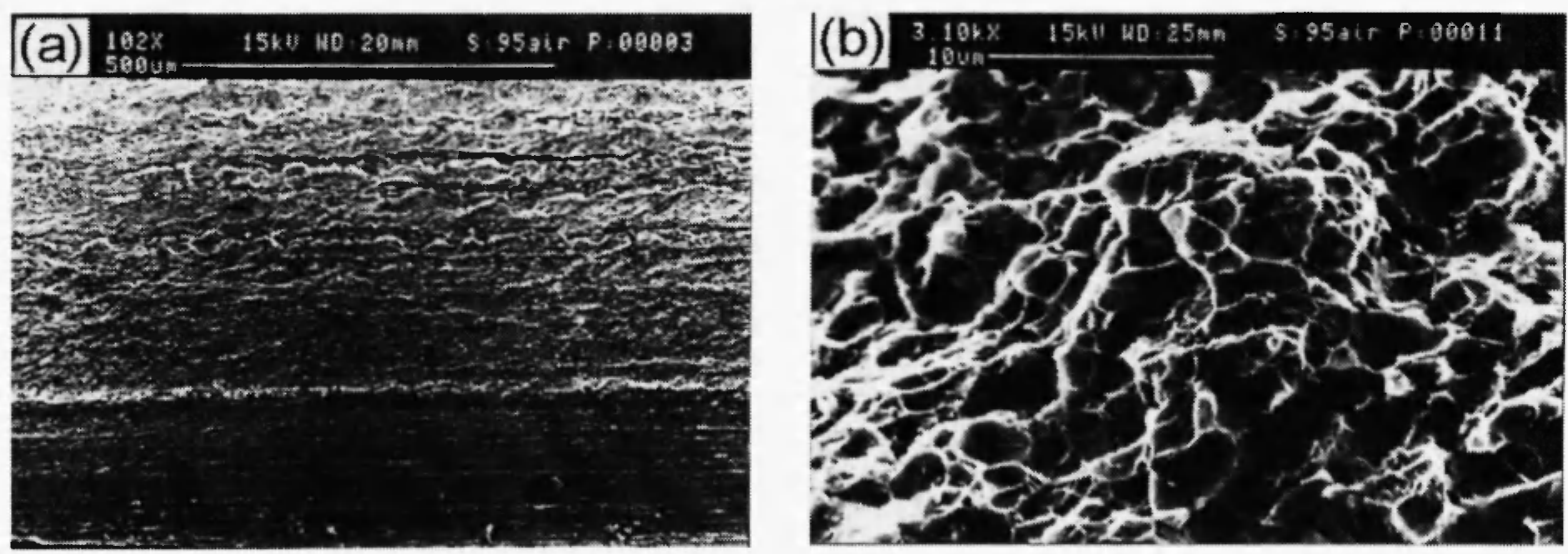

Fig. 3: Scanning electron micrographs showing fracture surface morphology of (a) backside junction layer and (b) DXZ section of FSW AA 2195 tested in laboratory air.

(a)
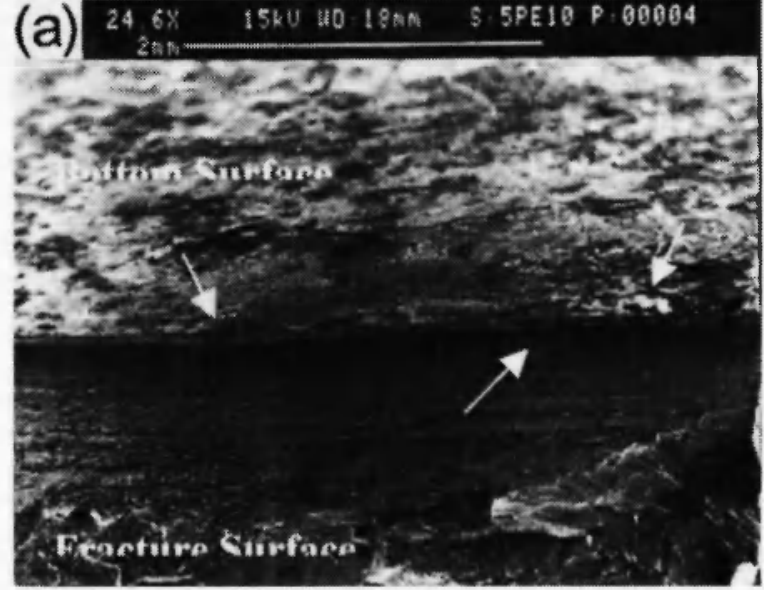

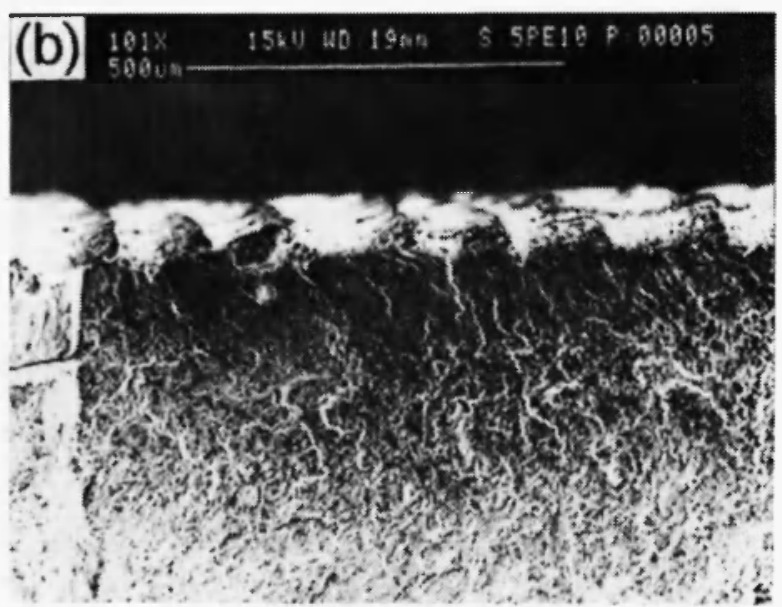

Fig. 4: Scanning electron micrograph showing minor pitting (indicated by arrows) in (a) bottom junction line and (b) top surface of FSW Al 2195 that has been PE for 10 days in $3.5 \% \mathrm{NaCl}$ solution. 

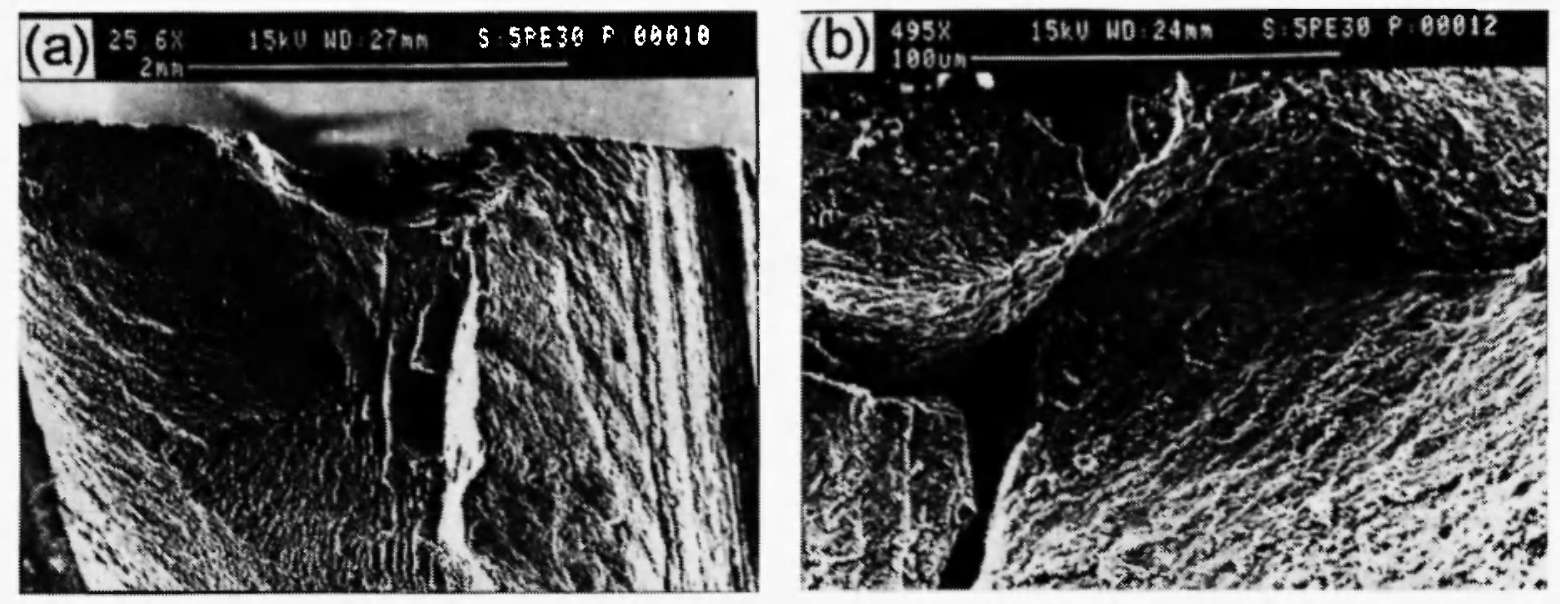

Fig. 5: Scanning electron fractographs from a specimen that was pre-exposed for 30 days; (a) overall view of fracture surface (a pit is on the top; the bottom layer is on the right side) and (b) area in front of the corrosion pit (left top side) showing brittle fracture and secondary cracking.

The results of the constant immersion and dynamic charging experiments showed no ductility reductions under the testing conditions. SEM examinations revealed ductile fracture modes similar to those observed in laboratory air experiments. However, the pre-exposed specimens exhibited ductility reductions that increased with increasing exposure time. SEM examinations revealed no pitting in specimens that were pre-exposed for 1 day. Sporadic pitting occurred after 10- and 30-day pre-exposures. For example, Figure 4(a) shows a corrosion pit that developed in the bottom joint line of a specimen that was pre-exposed for 10 days. Closer examination of the fracture surface immediate to the pit showed no differences in appearance from that of the same region in specimens tested in laboratory air, Figure 3(a). As mentioned earlier, this can be the weakest section of the weld and typically fracture initiates there. In view of the latter and the fact that this layer is very small compared to the rest of the weld, it can be concluded that corrosion in this section may have contributed to faster crack initiation but was not the main reason for the observed susceptibility. Similar observations on the top section (SDXZ) of pre-exposed specimens, Figure 4(b), showed that ductile fracture was present in the vicinity of the pits, again suggesting that pitting on the top surface was also not responsible for the observed susceptibility.

Some interesting observations were made on the side surfaces (cross sectional surface) of the specimens that were pre-exposed for 10 and 30 days. Brittle transgranular cracking, Figure 5(a), followed pits that developed in the HAZ. Close examination of the fracture surface around the corroded area showed a flat, brittle fracture appearance with secondary cracks and no signs of corrosion, Figure 5(b). This type of brittle fracture seemed to have been initiated from a corrosion pit and extended for a long distance (more than 1 $\mathrm{mm}$ ) into the bulk material. It is not clear at this point if the observed brittle cracking was a direct result of 
the corrosion process at this site. The present observations, however, suggest that only pits that developed in the HAZ were able to produce such embrittlement. According to the TEM analysis, no $T_{1}$ precipitates were present in the welded zone but this phase exhibited coarsening in the HAZ. Furthermore, the OCP of $T_{1}$ in $3.5 \% \mathrm{NaCl}$ solution is $-1.10 \mathrm{~V}_{\mathrm{SCE}} / 19 /$, compared to an OCP of $-0.73 \mathrm{~V}_{\mathrm{SCE}}$ for the parent $\mathrm{Al} 2195 / 11 /$. Thus, the $T_{1}$ is anodic with respect to the matrix, and dissolution of coarse $T_{1}$ at grain and subgrain boundaries has been suggested to result in EAC via a dissolution mechanism /12/. However, such a process normally produces an intergranular cracking mode whereas the present results showed a flat, transgranular fracture. Also, it is difficult to account for the observed long crack propagation distances based on a dissolution process in view of the fact that no corrosion signs were present on the fracture surface. Furthermore, some susceptibility was present in specimens pre-exposed for just 1 day in spite of the absence of pitting.

The present results showed no ductility reductions for the constant immersion and dynamic charging experiments. However, both of these tests were of a significantly shorter duration (a couple of hours) compared to the PE tests ( 24 hours for the shorter PE). In addition, dynamic charging was conducted at a potential cathodic to the OCP of $T_{1}$ and thus no $T_{1}$ dissolution would have been expected. In addition, effective hydrogen entrance into the alloy critically depends on the surface conditions. Thus, it can be concluded that in the constant immersion and dynamic charging tests, corrosion processes and/or hydrogen effects were not developed at a significant level to influence the EAC behavior of the welded Al 2195 .

It is difficult to separate the possible contributions of dissolution and hydrogen embrittlement from the present results. However, a key role seems to be played by the $T_{1}$ precipitates as has been proposed previously for other $\mathrm{Al}-\mathrm{Li}$ alloys $/ 12,13,17 \%$. It is characteristic to note that $\mathrm{EAC}$ in the present study was observed to initiate only in the zone that contained coarse $T_{1}$ precipitates (HAZ). In aerated chloride solutions, $T_{1}$ is electrochemically active with respect to the Al matrix and is polarized anodically. Under these conditions, the elements involved in $\mathrm{T}_{1}(\mathrm{Al}, \mathrm{Cu}, \mathrm{Li})$ dissolve but the $\mathrm{Cu}$ ions plate back on the alloy surface in the vicinity of the particle $/ 20 \%$. This has been manifested by copper colored (reddish) surfaces that have been observed to develop in dry-polished $\mathrm{T}_{1}$ contacted with water $/ 19 /$ and in Al-Li-Cu alloys preexposed under alternate immersion in chloride solutions $/ 13 /$. These copper deposits are expected to enhance cathodic reaction kinetics /16/. The hydrogen over-voltage for copper is very low (190 mV) and the hydrogen exchange current density on copper is three orders of magnitude higher than that on aluminum. Under these conditions, hydrogen discharge and subsequent entry into the alloy leading to embrittlement can occur. The present experimental data and fracture surface morphology are consistent with that view rather than dissolution since the latter would have produced an intergranular cracking mode. Further support for embrittlement by hydrogen is provided by previous experiments conducted on $\mathrm{Al}-3 \mathrm{Li}-\mathrm{ICu}$ alloy $/ 13 / . \mathrm{After}$ a pre-exposure stage, specimens were either strained in air exhibiting significant ductility reductions, or were given the full heat treatment cycle and then strained in air. The latter specimens recovered their ductility, showing that the pre-exposure embrittlement can be reverted.

The reason that no ductility reductions were detected in the dynamic charging experiments can relate to the unfavorable conditions for hydrogen reduction kinetics existing on the alloy surface. No $T_{1}$ dissolution is 
expected at the applied cathodic potential and thus no $\mathrm{Cu}$ deposits would have been produced to facilitate hydrogen reduction kinetics and ingress in the alloy. It should be noted that, even though at a lower pace, hydrogen is expected to enter the alloy under these conditions, as has been experimentally observed recently by conducting lattice expansion studies of statically charged $\mathrm{Al} 2195$ specimens at $-1.5 \mathrm{~V}_{\mathrm{SCE}} / 2 \mathrm{l}$. However, the results show that for the given alloy microstructure/properties, the hydrogen content is not sufficient to induce embrittlement. Another reason may also lie in the characteristics of the hydrogen distribution in the alloy. Cathodic charging would produce less hydrogen (slow kinetics) and dispersed (low concentration) since it is to be generated on the entire alloy surface. On the contrary, more hydrogen is to be generated on $\mathrm{Cu}$ deposits (enhanced kinetics), which is also localized (high concentration) thus being more effective in producing EAC susceptibility. It should be noted that in previous studies, Al 2090 was found to exhibit higher EAC susceptibility under similar dynamic charging condition $/ 16 /$. The difference in this behavior is attributed to lower fracture toughness and higher $\mathrm{Li}$ content of $\mathrm{Al} 2090$. As noted earlier, the higher $\mathrm{Li}$ content results in coarse $T_{1}$ and other $T$-type precipitates nucleating and growing preferentially at grain and subgrain boundaries $/ 12,17 /$. Thus, in this particular microstructure, dissolution of grain boundary T-type precipitates (or even coarse $T_{1}$ ) is possible at the charging potential producing $\mathrm{Cu}$ deposits that can facilitate the hydrogen cathodic reaction. Furthermore, even in the presence of smaller hydrogen content in this case, embrittlement would have been possible in view of the lower fracture toughness of the $2090 \mathrm{Al}$ alloy.

\section{CONCLUSIONS}

FSW processed AA 2195 exhibited a dynamically recrystallized equiaxed grain structure. No $T_{1}$ precipitates were present, suggesting that they were resolutionized during FSW processing. Slow extension rate experiments under constant immersion and dynamic charging conditions showed no ductility reductions for FSW AA 2195. Pre-exposure under alternate immersion followed by slow extension rate testing showed a certain degree of environmental susceptibility that increased with increasing pre-exposure time. EAC was associated with the HAZ where coarser $T_{1}$ precipitates were present. The observed behavior was attributed to coarse $T_{1}$ dissolution that can facilitate hydrogen reduction kinetics and ingress in the alloy resulting in susceptibility by hydrogen embrittlement.

\section{ACKNOWLEDGEMENTS}

This work was supported by Lockheed-Martin Space Systems (New Orleans, Louisiana). The TEM work was conducted in the LSU Materials Characterization Center supported by NSF grant DMR-9871417. The authors thank W.J. Arbegast for his comments. 


\section{REFERENCES}

1. C.J. Dawes. "An introduction to friction stir welding and its development", Welding and Metal Fab., 63, 13 (1995).

2. L.E. Murr, Y. Li, E.A. Trillo, B.M. Nowak and J.C. McClure. "A comparative study of friction-stir welding of aluminum alloys", Alumimum Trans. 1, 141 (1999).

3. M.W. Mahoney, C.G. Rhodes, J.G. Flintoff, R.A. Spurling and W.H. Bingel. "Properties of friction-stirwelded 7075 T651 aluminum", Metall. Mater. Trans. 29A, 1955 (1998).

4. W.J. Arbegast and P.J. Hartley. "Friction stir weld technology development at Lockheed Martin Michoud Space System-An overview", Trends in Welding Research, Materials Park: ASM International, 1999:541.

5. G. Liu, L.E. Murr, C.-S. Niou, J.C. McClure and F.R. Vega. "Microstructural aspects of the friction-stir welding of 6061-T6 aluminum", Scripta Mater. 37, 355 (1997).

6. Y. Li, L.E. Murr and J.C. McClure. "Solid state flow visualization in the friction stir welding of $2024 \mathrm{Al}$ to 6061 Al”, Scripta Mater. 40, 1041 (1999).

7. C.G. Rhodes, M.W. Mahoney, W.H. Bingel, R.A. Spurling and C.C. Bampton. "Effects of friction stir welding on microstructure of 7075 aluminum", Scripta Mater. 36, 69 (1997).

8. L.E. Murr, G. Liu and J.C. McClure. "Dynamic recrystallization in friction stir welding of aluminum alloy 1100", Mater. Sci. Lett. 16, 1801 (1997).

9. K.V. Jata. "Friction stir welding of high strength aluminum alloys", Materials Science Forum, Zürich: Trans Tech Publications, 331-337, 1701 (2000).

10. Z.X. Li, W.J. Arbegast, P.J. Hartley and E.I. Meletis. "Microstructure characterization and stress corrosion evaluation of friction stir welded Al 2195 and Al 2219 alloys", Trends in Welding Research, Materials Park: ASM International, 1999:568.

11. W. Hu and E.I. Meletis. "Corrosion and environmental-assisted cracking behavior of friction stir welded Al 2195 and Al 2219 alloys", Materials Science Forum, Zurich: Trans Tech Publications, 331-337, 1683 (2000).

12. R.G. Buchheit, F.D. Wall, G.E. Stoner and J.P. Moran. "Anodic dissolution-based mechanism for the rapid cracking, preexposure phenomenon demonstrated by aluminum-lithium-copper alloys", Corrosion 51, 417 (1995).

13. E.I. Meletis and W. Huang. "The role of the $T_{1}$ phase in the pre-exposure and hydrogen embrittlement of Al-Li-Cu alloys", Mater. Sci. Eng. A 148, 197 (1991).

14. R. Balasubramaniam, D.J. Duquette and K. Rajan. "On stress corrosion cracking in aluminum-lithium alloys", Acta Metall. Mater. 39, 2597 (1991).

15. K.S. Kumar, S.A. Brown and J.R. Pickens. "Microstructural evolution during aging of an Al-Cu-Li-AgMg-Zr alloy", Acta Mater. 44, 1899 (1996). 
16. E.I. Meletis. "Microstructural effects on the environment-assisted fracture mechanism of Al-Li alloys", Fundamental Aspects of Stress Corrosion Cracking. Warrendale: TMS-AIME, 1992:353.

17. E.I. Meletis. "Microstructure and stress corrosion cracking relationship in an Al-Li-Cu-Zr alloy", Mater. Sci. Eng. A 93, 235 (1987).

18. J.M. Silcock. "The structural ageing characteristics of aluminium-copper-lithium alloys", J. Inst. Met. 88, 357 (1959).

19. R.G. Buchheit, J.P. Moran and G.E. Stoner. "Electrochemical behavior of the $\mathrm{T}_{1}\left(\mathrm{AI}_{2} \mathrm{CuLi}\right)$ intermetallic compound and its role in localized corrosion of AI-2Li-3Cu alloys", Corrosion 50, 120 (1994).

20. R.G. Buchheit. "The electrochemistry of $\theta\left(\mathrm{Al}_{2} \mathrm{Cu}\right), \mathrm{S}\left(\mathrm{Al}_{2} \mathrm{CuMg}\right)$ and $\mathrm{T}_{1}\left(\mathrm{Al}_{2} \mathrm{CuLi}\right)$ and localized corrosion and environment assisted cracking in high strength Al alloys", Materials Science Forum, Zürich: Trans Tech Publications, 331-337, 1641 (2000).

21. L. Gan and E.I. Meletis. "Environment-assisted cracking of Al 2195 alloy", Materials Science Forum, Zürich: Trans Tech Publications, 331-337, 1619 (2000). 